\title{
Takayasu's arteritis in pregnancy: review of literature and discussion
}

\author{
Evelyn Hauenstein ${ }^{1,5} *$, Helga Frank ${ }^{2}$, Jan S. Bauer ${ }^{3}$, \\ K.T.M. Schneider ${ }^{1}$ and Thorsten Fischer ${ }^{1,4}$ \\ ${ }^{1}$ Department of Obstetrics and Gynecology, Technical \\ University of Munich, Ismaninger Str. 22, 81675 \\ München, Germany \\ ${ }^{2}$ Department of Nephrology, Technical University of \\ Munich, Ismaninger Str. 22, 81675 München, Germany \\ ${ }^{3}$ Department of Radiology, Technical University of \\ Munich, Ismaninger Str. 22, 81675 München, Germany \\ ${ }^{4}$ Krankenhaus Landshut-Achdorf, Frauenklinik, Achdorfer \\ Weg 3, 84036 Landshut, Germany \\ ${ }^{5}$ Klinikum Starnberg, Frauenklinik, Oswaldstraße 1, \\ 82319 Starnberg, Germany
}

\begin{abstract}
Takayasu's arteritis (TA) is a rare inflammatory disease of the arteries that affects women of childbearing age. The optimal management for pregnant patients with this disease has not yet been defined. The course of disease seems to be neither affected nor worsened by pregnancy. We could not find reported maternal deaths directly related to pregnancy. However, many authors report maternal as well as fetal unfavorable events in the course of pregnancy. We describe a 25year-old primigravida of Turkish-Greek origin who presented at 30 weeks of pregnancy with active TA. In the $37^{\text {th }}$ week, intrauterine fetal death occurred. Our patient did not show high blood pressure or aortic inflammation. The course of her disease was stable. Whether a newly diagnosed TA during pregnancy should be regarded as an indication for premature delivery is discussed. An interdisciplinary collaboration of rheumatologists, nephrologists and obstetricians is necessary to improve maternal and fetal prognosis.
\end{abstract}

\footnotetext{
*Corresponding author:

Evelyn Hauenstein, MD

Klinikum Starnberg

Frauenklinik

Oswaldstraße 1

82319, Starnberg

Germany

Tel.: + 49-8151-18-0

E-mail: evelyn.hauenstein@web.de
}

Keywords: Childbearing age; pregnancy; resistance index (RI); Takayasu's arteritis (TA).

\section{Introduction}

Takayasu's arteritis (TA) is an inflammatory disease of the arteries that affects women of childbearing age. It is a rare chronic vasculitis of unknown etiology, firstly described in 1908 by the Japanese ophthalmologist Mikito Takayasu. It has variable geographical distribution with the greatest prevalence in Asians, especially Japan, and the Orient. Women are affected in $80-90 \%$ of cases with a mean age of presentation in the second and third decade of life, reflected in a synonym for TA as "young female arteritis". It is not uncommon to encounter this disease during pregnancy.

Optimal management for pregnant patients with this disease has not yet been established. Due to the manifold cardiovascular complications that can occur in the course of the disease, management of pregnancies in TA patients is a challenge for the obstetrician, the rheumatologist and the cardiologist.

Four questions have not been fully answered yet:

- How to control a pregnancy in a TA patient? When is the optimal time for delivery and which is the best mode of delivery?

- Does the status of the disease improve, unchange, or worsen during pregnancy?

- How does a pregnancy affect the long-term prognosis of TA patients?

- How to achieve a good fetal outcome?

Guidelines for the treatment of pregnant women with TA are necessary. There are only few case reports in the literature about women who were diagnosed with TA during pregnancy. Since this is a rare, but not totally uncommon event, it might also be necessary to suggest guidelines for the treatment of these patients.

\section{Case report}

We describe a 25-year-old primigravida of Turkish-Greek origin who presented at 30 weeks of pregnancy with strong right-sided neck pain. The pain had been present together with numbness in the right half of her face since two days prior to first presentation. The painful feelings was also elicited by stretching her right arm. During the next days, the patient showed a right-sided facial paresis. On the right arm, 
a pulse could not be found. Pulses in all other areas were normal, heart auscultation revealed no abnormalities. Bruits over the right and left carotid were audible, louder on the right side. Blood pressure was $110 / 70 \mathrm{~mm} \mathrm{Hg}$ measured on the left arm, but could not be measured on the right arm. The patient had no fever. The neurological examination was normal.

Laboratory values showed a slightly elevated C-reactive protein $(16 \mathrm{mg} / \mathrm{L})$ and leukocyte count $(11.12 \mathrm{G} / \mathrm{L})$. Creatinine was $0.4 \mathrm{mg} / \mathrm{dL}$, alkaline phosphatase $143 \mathrm{U} / \mathrm{L}$, GOT $36 \mathrm{U} / \mathrm{L}$, fibrinogen $511 \mathrm{mg} / \mathrm{dL}$, d-dimers $222 \mu \mathrm{g} / \mathrm{L}$, hemoglobin $11.1 \mathrm{~g} / \mathrm{dL}$, hematocrit $33.4 \%$, thyrotropin 27.27 $\mathrm{uIU} / \mathrm{mL}$. All other values were normal.

Doppler scan of the head arteries showed a long vessel wall thickening of both common carotid arteries with stenosis of $50-60 \%$ up to the bifurcation. The intima-mediacomplex was $1.4 \mathrm{~mm}$ in the left arteria carotis communis (ACC) and $1.2 \mathrm{~mm}$ in the right ACC. The arteria carotis interna (ACI) and arteria carotis externa (ACE) on both sides were free. A complete closure of the right vertebral artery and high-grade stenosis of the right subclavian artery were also diagnosed. Doppler scan of the extremities showed a systolic pressure difference of $20 \mathrm{~mm} \mathrm{Hg}$ between the right $(70 \mathrm{~mm} \mathrm{Hg}$ ) and the left brachial artery $(90 \mathrm{~mm} \mathrm{Hg})$.

Native MRI of head (3 levels) and neck (2 levels) showed closure of the right vertebral artery and wall thickening of the left common carotid artery. No hints for fresh bleeding or older vascular lesions were seen (Figures 1 and 2).

A diagnosis of TA was made. Besides, the patient had a congested right kidney with urinary tract infection that was successfully treated with antibiotics, Hashimoto thyroiditis treated with euthyrox (Levothyroxin, Merck kGaA, Darmstadt, Germany) $100 \mu \mathrm{g}$ and mild gestational diabetes. Blood sugar values could be controlled by dietary measures.

Immunosuppressive therapy with high dose cortisone (methyl prednisolone $40 \mathrm{mg} / \mathrm{d}$ ) was started. Neck pain and facial paresis disappeared completely. Numbness in the right

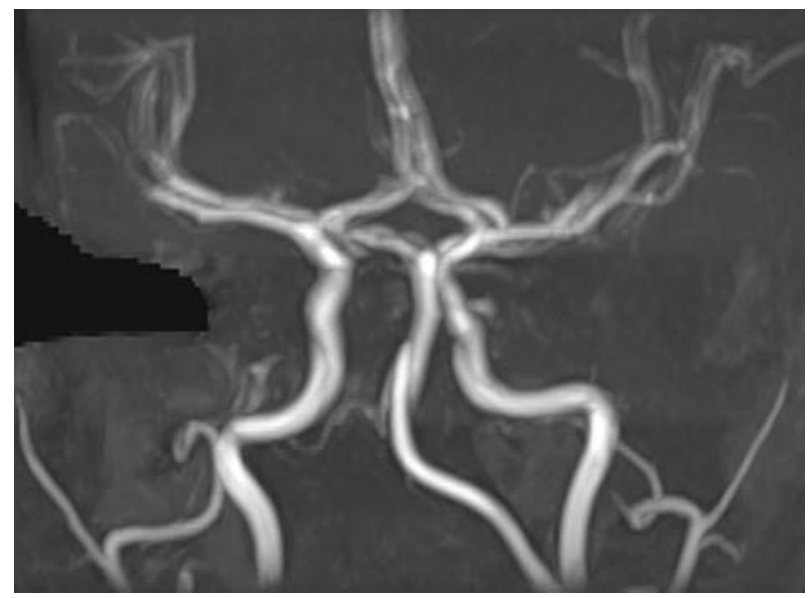

Figure 1 Native MRI of head (3 levels) shows a closure of the right vertebral artery.

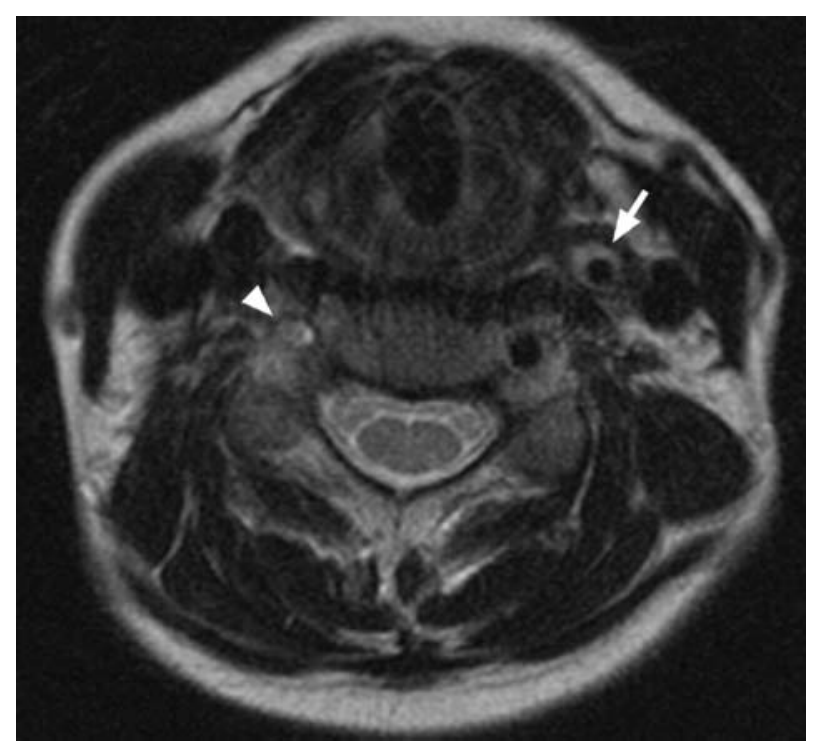

Figure 2 Native MRI of neck (2 levels) shows that the right vertebral artery is closed (arrowhead) and a wall thickening of the left common carotid artery (arrow). No hints for fresh bleeding or older vascular lesions can be seen.

half of face and right arm was still present, but decreased gradually. The arterial alterations described and the serologic parameters remained stable over two months, possibly not indicating an "active" onset phase, but rather a "burn-out" phase of TA. The pregnancy was controlled tightly in our clinic. Its course was uneventful except for a small for gestational age fetus, growing steadily on the fifth percentile. The ultrasound examination at $35+1$ weeks' gestation showed a $2027 \mathrm{~g}$ estimated weight. Doppler of the umbilical artery showed a resistance index (RI) of 0.63 with a positive end diastolic flow (EDF). The Doppler of maternal vessels showed a RI of 0.49 and a pulsatility index (PI) of 1.27 in the left uterine artery and a RI of $0.51 / \mathrm{PI}$ of 1.28 in the right uterine artery. In an interdisciplinary case conference, it was decided that no indication for premature delivery existed. Instead, induction of labor at $37+0$ weeks of gestation was recommended. We also recommended seeing her gynecologist for weekly cardiotocography and Doppler studies, but we do not know whether she was compliant. Contraction stress tests were not performed.

The patient was examined twice in our clinic (level one center for perinatal medicine): at initial presentation after TA had been diagnosed, and in $36+6$ weeks of gestation, the day before induction of labor was scheduled. On a routine sonography on her second admission, we diagnosed intrauterine fetal death. After induction of labor, the patient delivered a dead male fetus with the umbilical cord wrapped twice around the neck (weight $2050 \mathrm{~g}$, length $47 \mathrm{~cm}$ ). Pathology showed a growth restricted male fetus without internal or external malformation. Histological work-up of the placenta did not show manifestation of TA. 


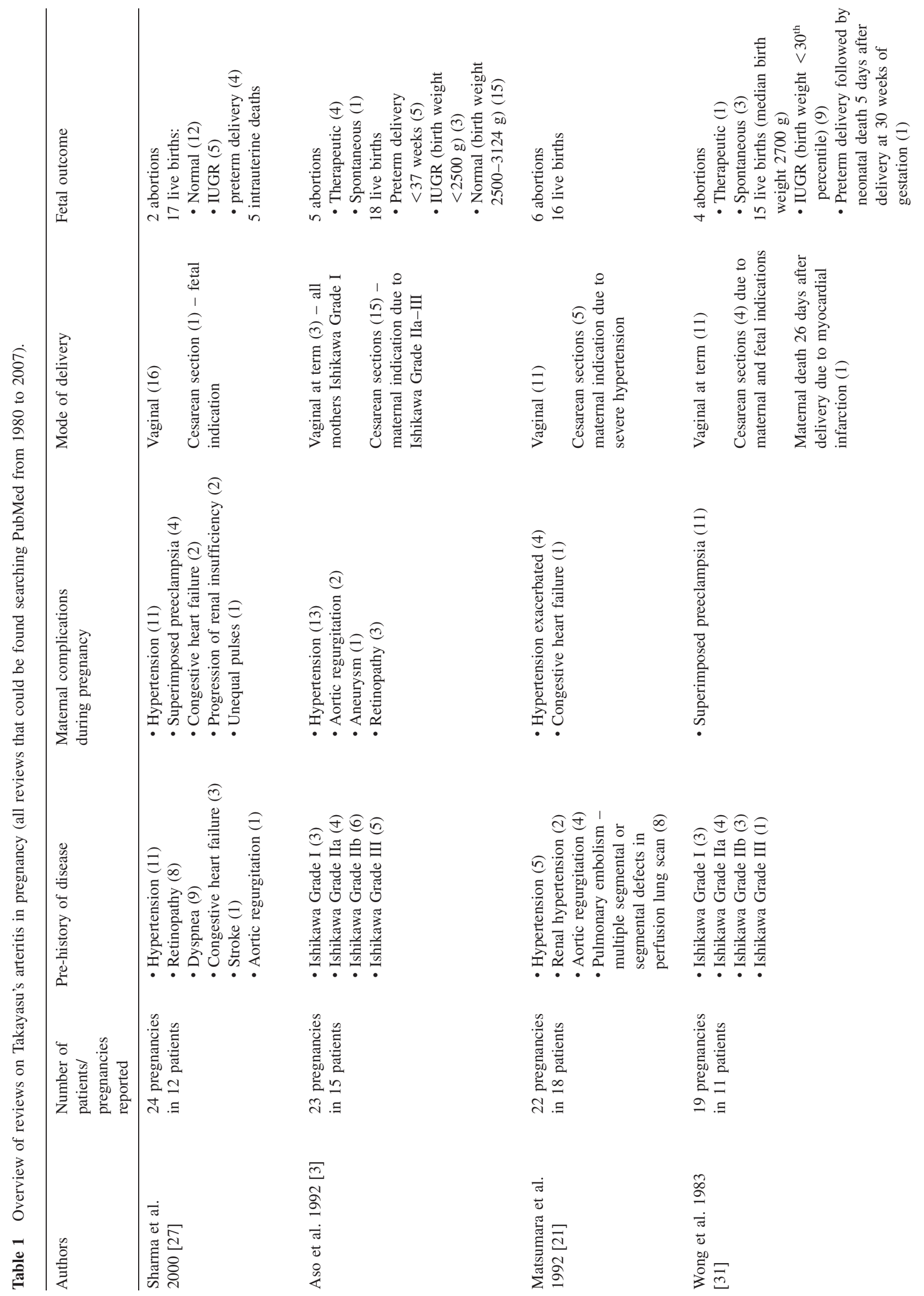




\section{Discussion}

Tables 1 and 2 describe all reviews published on TA in pregnancy in the literature from 1980 to 2007 searching the PubMed Database (http://www.ncbi.nlm.nih.gov/sites/ entrez). A literature search also revealed several well-documented case reports about TA patients in pregnancy (Table 4).

TA is a rare, chronic, giant-cell vasculitis which primarily involves the aorta, its main branches and coronary and pulmonary arteries. The disease causes various clinical conditions such as arm claudication, decreased artery pulses, carotodynia, visual loss, stroke, aortic regurgitation, hypertension and congestive heart failure. Clinical presentation may be insidious and diagnosis is often delayed. Table 3 shows the criteria for active disease according to Kerr [18]. In 1990, the American College of Rheumatology proposed six diagnostic criteria, at least three of them are required for classifying a patient as having TA (Table 4). Ishikawa classified TA patients according to the presence of complications at the time of first diagnosis and thus identified individual prognostic markers [15]. The natural course of TA is chronic and progressive, with a reported survival range of 1-15 years.

The etiology of TA is still unknown. The inflammatory lesions in TA originate in the vasa vasorum and are followed by cellular infiltration of the outer layer of the media and/or adventitia. So far, the antigen(s) that trigger(s) the autoimmune process could not be identified [23]. As far as we know, autoantibodies known to play a role in the pathogenesis of other vascular diseases - like ANCA antibodies in Wegener's granulomatosis - do not contribute to the development of TA. Possibly, antiendothelial autoantibodies are involved [23]. However, no laboratory tests for autoantibodies have been developed to date for the diagnosis of TA. The inflammatory reaction in TA responds to glucocorticoids which are the drugs of first choice in pregnancy [10]. If prednisone treatment fails, azathioprine should be considered. Hypertension should be treated very agressively with alpha-methyldopa, calcium channel blockers or hydralazine.

Pregnancy occurs more frequently in patients with TA than in patients with other forms of vasculitis. We could identify 137 cases of pregnant patients with TA in the literature. Fertility and the incidence of miscarriages are presumably unaffected by TA. A total of $12.4 \%$ of the pregnancies terminated with abortion, a third of those artificially because maternal hypertension could not be sufficiently controlled. In the studies we identified, no cases of direct maternal death related to pregnancy have been reported. However, many of the reports listed above describe unfavorable events: $30.6 \%$ suffered from uncontrolled and/or exacerbating hypertension, with superimposed preeclampsia being the most common (described in $19.7 \%$ of cases), followed by congestive heart failure (3.9\% of cases). Progression of renal insufficiency, intra- and antepartum hemorrhage, myocardial infarction, retinopathy, aortic regurgitation, aortic aneurysms and pulmonary embolism have also been reported in pregnant TA 


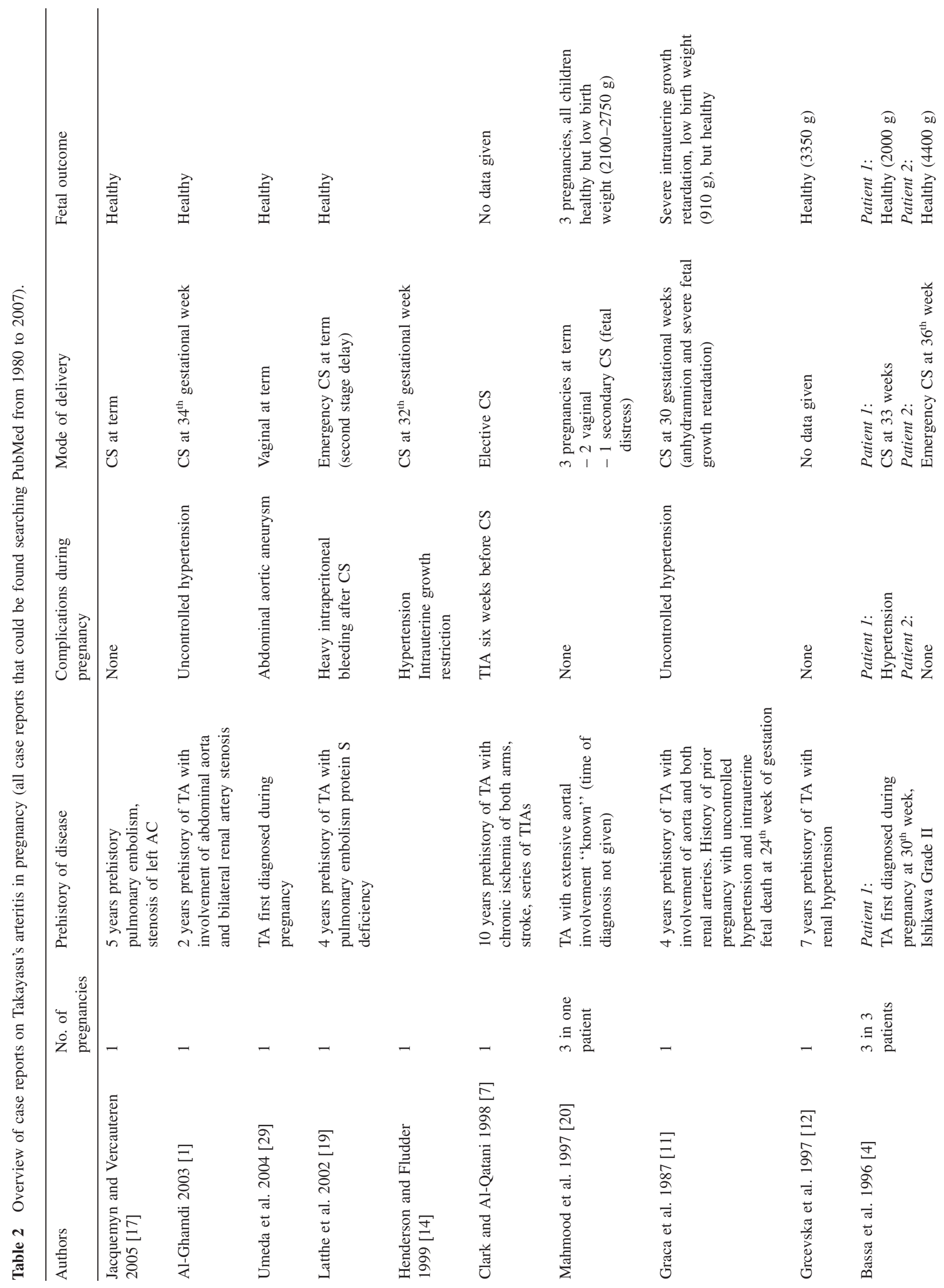




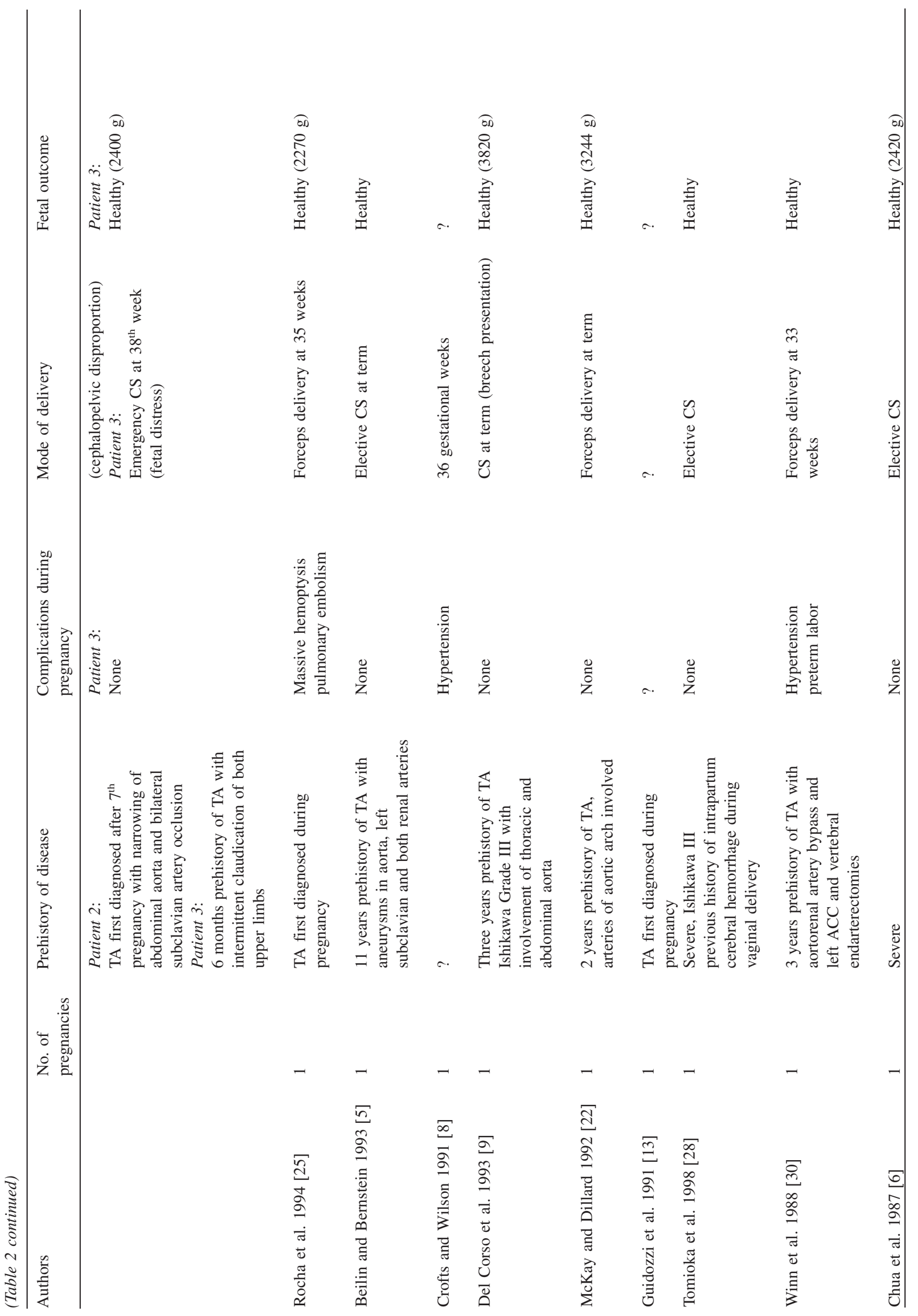


Table 3 Criteria for active disease (Kerr 1994).

- Features of vascular ischemia or inflammation (such as vascular pain (carotodynia), claudication, diminished or absent pulse, bruit), asymmetric blood pressure in either upper or lower limbs (or both)

- Elevated ESR

- Systemic features, such as fever, musculoskeletal (without any other cause identified)

- Typical angiographic features

- New onset or worsening of two or more features indicates "active disease"

Criteria for remission

- Complete resolution or stabilization of all clinical features

- Fixed vascular lesions

patients. Most of those unfavorable events occur in the perinatal period.

The course of disease seems to be unaffected or worsened by pregnancy $[16,21,26]$. However, it is yet unclear whether pregnancies affect the individual prognosis. So far, suitable criteria to predict the final maternal and fetal outcomes have not been developed. Many case reports show that even patients with multiple stenoses in major arteries have a chance of delivering a mature, normal baby. In $83.9 \%$ of the cases that we reviewed ended with delivery of a healthy child. In patients who were diagnosed as TA during pregnancy, the course of disease does not seem to be more aggressive from other TA patients. Induction of labor or cesarean section are not indicated for all pregnant TA patients [3]. In the 137 cases we reviewed, $40.8 \%$ of patients had a spontaneous vaginal delivery with good maternal and fetal outcome. Vaginal delivery at term has been recommended in a recent publication [24]. However, the fact that systolic blood pressure rises significantly during the second stage of labor should be considered [27]. A total of $9.7 \%$ of patients in the cases reviewed had a forceps or vacuum delivery, in most instances performed in order to shorten the second stage of labor and as many as $37.6 \%$ of patients were delivered by cesarean section. Regarding the influence of TA on the fetus, intrauterine growth restriction has been reported in $19.7 \%$ of cases, most probably due to decreased uterine perfusion as a consequence of arterial disease [20, 26]. Six intrauterine fetal deaths have also been reported, representing $8.2 \%$ of cases $[11,27]$.

Our patient fulfilled all ACR criteria for the diagnosis of TA: she was under 40 years of age, felt fatigue and muscle discomfort in the right arm, showed a systolic pressure difference of $20 \mathrm{~mm} \mathrm{Hg}$ between arms, pulse of the right brachial artery could not be felt, bruit was audible over both carotid arteries, and the MRI examination showed vessel abnormalities. However, she did not fulfill any of the criteria defined by Sharma et al. [27] indicating a bad prognosis for pregnancy. Our patient did not have high blood pressure or aortal inflammation. The course of her disease was stable, and the pregnancy uneventful. Placental histology did not show any manifestations of TA. However, we do not regard the fetal death merely as an unfortunate coincidence with TA. Other mechanisms - like vascular damage on the maternal side restricting fetal nutrition but not manifesting itself in placental histology - could have played a role. It is hard to believe that the onset of a severe vascular disease in the middle of pregnancy has not contributed to the outcome. At the very least, the diagnosis of TA should have led to tighter surveillance of the pregnancy. As we want to show by reporting our case, management of such pregnancies - even though our patient suffered no major complications of TA - should not be taken lightly. Tight cardiotocography and ultrasound control should be scheduled. Possibly, fetal death could have been avoided in our case had the patient been hospitalized or controlled at least twice weekly in a level I center for perinatal medicine. Regarding the unfavorable outcome, it should be discussed if a newly diagnosed TA during pregnancy should not by itself be regarded as an indication for elective premature delivery. An interdisciplinary collaboration of rheumatologists, nephrologists and obstetricians is necessary to improve maternal and fetal outcome.

Table 41990 ACR criteria for the classification of Takayasu's arteritis (Arend et al. 1999).

\begin{tabular}{|c|c|}
\hline Criteria & Definition \\
\hline Age at disease onset in years & $\begin{array}{l}\text { Development of symptoms or findings related to Takayasu arteritis } \\
\text { at age }<40 \text { years }\end{array}$ \\
\hline Claudication of extremities & $\begin{array}{l}\text { Development and worsening of fatigue and discomfort in muscles of } \\
\text { one or more extremity while in use, especially the upper extremities }\end{array}$ \\
\hline Decreased brachial artery pulse & Decreased pulsation of one or both brachial arteries \\
\hline BP difference $>10 \mathrm{~mm} \mathrm{Hg}$ & Difference of $>10 \mathrm{~mm} \mathrm{Hg}$ in systolic blood pressure between arms \\
\hline Bruit over subcavian arteries or aorta & $\begin{array}{l}\text { Bruit audible on auscultation over one or both subclavian arteries or } \\
\text { abdominal aorta }\end{array}$ \\
\hline Arteriogram abnormality & $\begin{array}{l}\text { Arteriographic narrowing or occlusion of the entire aorta, its primary } \\
\text { branches, or large arteries in the proximal upper or lower extremities, } \\
\text { not due arteriosclerosis, fibro-muscular dysplasia, or similar causes: } \\
\text { changes usually focal or segmental }\end{array}$ \\
\hline
\end{tabular}




\section{References}

[1] Al-Ghamdi AA. Successful pregnancy in a patient with Takayasu's arteritis. Saudi Med J. 2003;24:1250-3.

[2] Arend WP, Michel BA, Bloch Da, Hunder GG, Calabrese LH, Edworthy SM, et al. The American College of Rheumatology 1990 criteria for the classification of Takayasu's arteritis. Arthritis Rheum. 1999;33:1129-34.

[3] Aso T, Abe S, Yaguchi T. Clinical gynecologic features of pregnancy in Takayasu arteritis. Heart Vessels Suppl. 1992;7: 125-32.

[4] Bassa A, Desai DK, Moodley J. Takayasu's disease and pregnancy. Three case studies and a review of the literature. S Afr Med J. 1996;85:107-12.

[5] Beilin Y, Bernstein H. Successful epidural anaesthesia for a patient with Takayasu's arteritis presenting for caesarean section. Can J Anaesth. 1993;40:64-6.

[6] Chua S, Viegas OA, Tan AT, Ratnam SS. Successful outcome of pregnancy in a subfertile patient with severe aortoarteritis (Takayasu's disease). Eur J Obstet Gynecol Reprod Biol. 1987;25:249-53.

[7] Clark AG, Al-Qatani M. Anaesthesia for caesarean section in Takayasu's disease. Can J Anaesth. 1998;45:377-9.

[8] Crofts SL, Wilson E. Epidural analgesia for labour in Takayasu's arteritis. Br J Obstet Gynaecol. 1991;98:408-9.

[9] Del Corso L, De Marco S, Vannini A, Pentimone F. Takayasu's arteritis: low corticosteroid dosage and pregnancy - a case report. Angiology. 1993;44:827-31.

[10] Doria A, Iaccarino L, Ghirardello A, Arienti S, Zampieri S, Rampudda ME, et al. [Rare autoimmune rheumatic illnesses during pregnancy: systemic sclerosis, polymyositis/dermatomyositis and vasculitis] - Seltene autoimmune rheumatische Erkrankungen in der Schwangerschaft. Systemische Sklerose, Polymyositis/Dermatomyositis und Vaskulitiden. Z Rheumatol. 2006;65:200-8.

[11] Graca LM, Cardoso MC, Machado FS. Takayasu's arteritis and pregnancy: a case of deleterious association. Eur J Obstet Gynecol Reprod Biol. 1987;24:347-51.

[12] Grcevska L, Polenakovic M, Dzikova S. Successful pregnancy and long-term follow-up (12 years) in a patient with Takayasu arteritis and renovascular hypertension as a first clinical sign. Clin Nephrol.1997;48:66-7.

[13] Guidozzi F, Louridas G, Grant MG, Koller AB, King P, Naylor S. Takayasu's arteritis in a pregnant woman. A case report. S Afr J Surg. 1991;29:159-60.

[14] Henderson K, Fludder P. Epidural anaesthesia for caesarean section in a patient with severe Takayasu's disease. Br J Anaesth. 1999;83:959-65.

[15] Ishikawa K. Natural history and classification of occlusive thromboaortopathy. Circulation. 1978;57:27-35.

[16] Ishikawa K, Matsura S. Occlusive thormboaortopathy
(Takayasu's disease) and pregnancy - clinical course and management of 33 patients and deliveries. Am J Cardiology. 1982;50:1293-300.

[17] Jacquemyn Y, Vercauteren M. Pregnancy and Takayasu's arthritis of the pulmonary artery. J Obstet Gynaecol. 2005;25: $63-5$.

[18] Kerr G. Takayasu's arteritis. Curr Opin Rheumatol. 1994;6: $32-8$.

[19] Latthe PM, Kilby M, Jobanputra P, Alner M. Pregnancy in Takayasu's arteritis with thrombophilia. J Obstet Gynaecol. 2002;22:228-9.

[20] Mahmood T, Dewart PJ, Ralston AJ, Elstein M. Three successive pregnancies in a patient with Takayasu's arteritis. J Obstet Gynaecol. 1997;17:53-4.

[21] Matsumura A, Moriwaki R, Numano F. Pregnancy in Takayasu arteritis from the view of internal medicine. Heart Vessels Suppl. 1992;7:20-4.

[22] McKay RSF, Dillard SR. Management of epidural anaesthesia in a patient with Takayasu's disease. Anaesthesia and Analgesia. 1992;74:297-9.

[23] Noris M. Pathogenesis of Takayasu's arteritis. J Nephrol. 2001;14:506-13.

[24] Papantioniou N, Katsoulis I, Papageorgiou I, Antsaklis A. Takayasu arteritis in pregnancy: safe management options in antenatal care. Case report. Fetal Diagn Ther. 2007;22:449_ 51.

[25] Rocha MP, Guntupalli KK, Moise KJ, Lockett LD, Khawli F, Rokey R. Massive hemoptysis in Takayasu's arteritis during pregnancy. Chest. 1994;106:1619-22.

[26] Seo P. Pregnancy and vasculitis. Rheum Dis Clin North Am. 2007;33:299-317.

[27] Sharma BK, Jain S, Vasishta K. Outcome of pregnancy in Takayasu arteritis. Int J Cardiol. 2000;75:S159-62.

[28] Tomioka N, Hirose K, Abe E, Miyamoto N, Araki K, Nomura $\mathrm{R}$, et al. Indications for peripartum aortic pressure monitoring in Takayasu's diseases. A patient with past history of intrapartum cerebral hemorrhage. Jpn Heart J. 1998;39:255-60.

[29] Umeda Y, Mori Y, Takagi H, Iwata H, Fukumoto Y, Hirose H. Abdominal aortic aneurysm related to Takayasu arteritis during pregnancy. Heart Vessels. 2004;19:155-6.

[30] Winn HN, Setaro JF, Mazor M, Reece A, Black HR, Hobbin JC. Severe Takayasu's arteritis in pregnancy: the role of central hemodynamic monitoring. Am J Obstet Gynaecol. 1988; 159:1135-6.

[31] Wong VCW, Wang RYC, Tse TF. Pregnancy and Takayasu's arteritis. Am J Med. 1983;75:597-601.

The authors stated that there are no conflicts of interest regarding the publication of this article.

Received January 19, 2009. Revised May 2, 2009. Accepted May 30, 2009. Previously published online August 13, 2009. 